\title{
PENGEMBANGAN BAHAN AJAR DENGAN MODEL CHILDREN LEARNING IN SCIENCE (CLIS) UNTUK MENINGKATKAN AKTIVITAS DAN KETERAMPILAN PROSES SAINS PESERTA DIDIK
}

\author{
Lina Hartati ${ }^{*}$., Mustika Wati ${ }^{2}$, Suyidno ${ }^{3}$ \\ 1,2,3Pendidikan Fisika FKIP Universitas Lambung Mangkurat, Banjarmasin, Indonesia \\ e-mail: lenyhartati18@gmail.com \\ e-mail: mustikawati_pfis@ulm.ac.id \\ e-mail: suyidno_pfis@ulm.ac.id
}

$\begin{array}{lll}\text { Submit } & : 10-02-2021 & \text { Revision : 21-03-2021 } \\ \text { Accepted } & : 26-03-2021 & \text { Published : 01-04-2021 }\end{array}$

*Corresponding author: Lina Hartati

\begin{abstract}
Abstrak: Minimnya ketersediaan bahan ajar yang mampu menumbuhkan aktivitas peserta didik menyebabkan keterampilan proses sains belum terlatih. Oleh karena itu, penelitian ini bertujuan menghasilkan bahan ajar dengan model Children Learning in Science (CLIS) yang layak untuk meningkatkan aktivitas dan keterampilan proses sains peserta didik. Desain bahan ajar ini menggunakan model ADDIE. Subjek uji coba ada 30 orang peserta didik kelas XI MIPA 3 SMAN 8 Banjarmasin. Data dianalisis secara kuantitatif. Pengumpulan data melalui lembar validasi pakar, pengamatan pembelajaran, pengamatan aktivitas dan keterampilan proses peserta didik, serta tes hasil belajar. Hasil penelitian menunjukkan; (1) hasil validasi RPP, materi ajar, LKPD, dan tes hasil belajar berkategori valid, (2) keterlaksanaan RPP berkategori sangat baik, (3) aktivitas dan keterampilan proses sains peserta didik berkategori sangat baik. Selain itu, $N$-gain hasil belajar kognitif sebesar 0,62 berkategori sedang. Diperoleh simpulan bahwa bahan ajar dengan model CLIS adalah layak untuk meningkatkan aktivitas dan keterampilan proses sains peserta didik.
\end{abstract}

Kata kunci: aktivitas, kelayakan bahan ajar, keterampilan proses sains

\section{DEVELOPMENT OF TEACHING MATERIALS WITH THE CHILDREN LEARNING IN SCIENCE (CLIS) MODEL TO IMPROVE THE ACTIVITY AND SKILLS OF THE SCIENCE PROCESS OF STUDENTS}

\begin{abstract}
The lack of availability of teaching materials that can foster student activity causes science process skills to be untrained. Therefore, research is aimed at teaching materials with the Children Learning in Science (CLIS) model is feasible to improve the students' activities and science process skill. This development design uses the ADDIE model. The trial subjects were 30 students of class XI MIPA 3 SMAN 8 Banjarmasin. Data were analyzed quantitatively. Data collectoin was through validation sheets, observation of lesson plans, activity observation and students' science process skills, learning achievement tests. The results showed; (1) the validation results of lesson plan, worksheet, teaching materials, and assessment test were valid, (2) the implementation of lesson plan was very good, (3) the activities and the students' science process skills in the category are very good. Other than that N-gain of the learning outcomes of 0.62 are in the medium category. It was concluded that teaching material with the CLIS model is feasible to increase the students' activities and science process skills.
\end{abstract}

Keywords: activities, teaching materials, science process skills 
Hartati, L., Wati, M., \& Suyidno. (2021). Pengembangan Bahan Ajar dengan Model Children Learning in Science (CLIS) untuk Meningkatkan Aktivitas dan Keterampilan Proses Sains Peserta Didik.

\section{PENDAHULUAN}

Pendidik mempunyai peran penting untuk membangun pola pikir dan pola sikap manusia, karena mereka dapat mencetak sumber daya manusia yang profesional sehingga menjadikan sebuah bangsa maju dengan sains dan teknologinya. Oleh karena itu setiap pendidik harus mengembangkan kemampuan diri dalam bidang fisik, batin, dan moral (Rosa, 2015). Dari segi proses, pendidik disebut berhasil jika mengikutsertakan peserta didik secara aktif, baik fisik, intelektual, dan sosial dalam pembelajaran. Dari segi hasil, pendidik dinyatakan berhasil jika proses belajar mengajar yang diberikan dapat mengubah perilaku peserta didik ke arah penguasaan kompetensi dasar yang lebih baik (Fahmi \& Irhasyuarna, 2019).

Pendidikan modern lebih menitikberatkan pada aktivitas (Fahmi dkk., 2019; Maulida dkk., 2020). Peserta didik akan belajar sambil bekerja, dimana pada proses bekerja, peserta didik akan memperoleh pengetahuan, pemahaman, keterampilan, serta perubahan perilaku, termasuk sikap dan nilai (Fahmi, 2016; Ningtyas dkk., 2020). Perkembangan aktivitas merupakan suatu upaya yang sangat penting dilakukan dan dapat terwujud apabila peserta didik terlibat secara aktif dalam proses pembelajaran (Purnamasari dkk., 2018; Santoso \& Wulandari, 2020).

Aktivitas dalam pembelajaran Fisika tidak lepas dari suatu eksperimen yang dapat meningkatkan keterampilan proses sains (KPS) (Elnada dkk., 2016; Rahmawati dkk., 2020). KPS ialah keterampilan proses yang mengaitkan keterampilan kognitif yaitu proses peserta didik menggunakan pikirannya, manual yaitu dalam menggunakan alat dan bahan, pengukuran, atau perakitan alat, dan sosial yaitu kerjasama (Mahfuziannor dkk., 2014). KPS sangat penting bagi peserta didik untuk menumbuhkan sains dan diharapkan memberikan pengetahuan baru atau mengembangkan pengetahuan yang dimiliki (Manu \& Nomleni, 2018;).

Pembelajaran Fisika perlu direncanakan agar aktivitas dan KPS peserta didik dapat terlaksana dan dapat mencapai hasil belajar yang ditetapkan. Pendidik harus mempersiapkan dahulu bahan pembelajaran sebelum mengajar di kelas. Melalui bahan ajar tersebut, terlihat isi yang akan disampaikan pada peserta didik, sehingga terjadi pertumbuhan kompetensi terhadap materi yang diajarkan dan dapat meningkatkan aktivitas dan KPS (Chodijah dkk., 2012).

Berdasarkan realitas pendidikan saat ini, aktivitas peserta didik masih kurang aktif dan KPS peserta didik masih sangat rendah. Bahan ajar yang digunakan seperti materi ajar hanya bersumber dari buku paket yang diperoleh dari penerbit tertentu di mana cakupan materinya masih bersifat umum, LKPD dan latihan soal jarang diberikan, serta dalam kegiatan pembelajaran kurang melibatkan peserta didik. Hal ini berdampak pada rendahnya hasil belajar yang dilihat dari perolehan nilai ulangan tengah semester. Pada mata pelajaran Fisika, belum ada satupun peserta didik yang mendapatkan nilai di atas kriteria ketuntasan minimal (KKM) yaitu sebesar 75.

Salah satu upaya meningkatkan aktivitas dan KPS peserta didik adalah dikembangkannya bahan ajar dengan model pembelajaran inovatif yang sesuai dengan karakteristik peserta didik dan materi ajar seperti model Children Learning in Science (CLIS). Model CLIS merupakan model pembelajaran yang berpusat pada peserta didik. Pendidik memfasilitasi serta membimbing agar pembelajaran berjalan lancar dan membimbing peserta didik agar mereka tidak melakukan aktivitas yang menyangkut fisik saja, tetapi juga aktivitas yang menuntun untuk berpikir (Renjani dkk., 2018).

Model CLIS terdiri atas lima tahap yaitu orientasi, pemunculan gagasan, penyusunan ulang gagasan, penerapan gagasan, dan pemantapan gagasan (Joko dkk., 2013). Kelebihan model CLIS yaitu dapat membiasakan belajar mandiri dalam menyelesaikan masalah, menumbuhkan kreatifitas belajar, membiasakan saling bekerja sama dan terlibat secara langsung dalam melakukan kegiatan, serta bagi pendidik pembelajaran dapat semakin lancar karena menumbuhkan suasana pembelajaran yang lebih aktif sehingga dapat membangun aktivitas dan KPS peserta didik (Marlina dkk., 2013). Selain itu, model ini dapat memberikan peningkatan hasil belajar, peningkatan keterampilan proses sains, dan peningkatan aktivitas peserta didik (Utami dkk., 2015). Diperkuat dari hasil penelitian Ismail (2017) bahwa KPS di salah satu SMA di kabupaten Bekasi meningkat setelah diterapkan model pembelajaran CLIS berbantuan multimedia berdasarkan hasil analisis data diperoleh rata-rata $\mathrm{N}$-gain keterampilan proses sains sebesar 57,00\% untuk kelas eksperimen dan 49,00\% untuk kelas kontrol. Hasil penelitian Laili dkk. (2015) menerangkan bahwa model CLIS berpengaruh terhadap aktivitas belajar Fisika di SMA Negeri 1 Jenggawah dengan aktivitas peserta didik kelas eksperimen lebih baik daripada kelas kontrol. Hasil penelitian Hidayati dkk. (2015) menjelaskan model CLIS dalam pembelajaran di kelas XI IPA SMAN 3 Palembang dapat meningkatkan hasil belajar. 
Berdasarkan uraian di atas, penelitian ini bertujuan untuk menghasilkan bahan ajar dengan model Children Learning in Science (CLIS) yang layak untuk meningkatkan aktivitas dan keterampilan proses sains peserta didik. Bahan ajar ini diharapkan dapat meningkatkan kualitas dan manfaatnya bagi dunia pendidikan terutama dalam bidang pendidikan sains.

\section{METODE PENELITIAN}

Jenis penelitian ini adalah penelitian dan pengembangan dengan model ADDIE yang terdiri dari analyze, design, develop, implement, dan evaluate. Subjek penelitian adalah peserta didik kelas XI MIPA 3 SMAN 8 Banjarmasin berjumlah 30 orang. Objek penelitian adalah kelayakan bahan ajar dengan model CLIS berupa validitas, kepraktisan, dan efektivitas. Instrumen penelitian ini yaitu lembar validasi bahan ajar untuk mengetahui validitas bahan ajar, lembar keterlaksanaan RPP untuk mengetahui kepraktisan bahan ajar, serta lembar pengamatan aktivitas dan KPS serta lembar tes hasil belajar untuk mengetahui efektivitas bahan ajar.

Sebelum diuji coba, bahan ajar terlebih dahulu di validasi oleh dua validator akademisi dan satu validator praktisi, kemudian dihitung reratanya dan disesuaikan dengan kriteria: $X \leq 1,6$ (tidak valid); $1,6<X \leq 2,2$ (kurang valid); $2,2<X \leq 2,8$ (cukup valid); $2,8<X \leq 3,4$ (valid); dan $X>3,4$ (sangat valid). Selain itu, diuji reliabilitasannya menggunakan rumus Alpha Cronbach dengan kriteria: $0,00 \leq$ sangat rendah $<0,20 ; 0,20 \leq$ rendah $<0,40 ; 0,40 \leq$ cukup $<0,60 ; 0,60 \leq$ ting $i<$ 0,80 ; dan $0,80 \leq$ sangat ting $i \leq 1,00$ i (Arikunto, 2014).

Setelah dilakukan revisi berdasarkan masukan validator, dilakukan uji coba bahan ajar dengan menggunakan one group pretest-posttest: $\mathrm{O}_{1} \mathrm{X} \mathrm{O}_{2}$. Pembelajaran diawali dengan pre-test hasil belajar $\left(\mathrm{O}_{1}\right)$. Selanjutnya diterapkan bahan ajar dengan model CLIS sebanyak 4 kali pertemuan (X). Selama proses pembelajaran, dilakukan pengamatan keterlaksanaan RPP, aktivitas, dan KPS peserta didik oleh 2 pengamat yang sudah terlatih. Pembelajaran diakhiri dengan post-test hasil belajar $\left(\mathrm{O}_{2}\right)$.

Data pengamatan keterlaksanaan RPP, aktivitas, dan KPS dihitung skor reratanya dan disesuaikan dengan kriteria: tidak baik $\leq 20,00 ; \quad 20,00<$ kurang baik $\leq 40,00 ; \quad 40,00<$ cukup baik $\leq 60,00 ; 60,00<$ baik $\leq 80,00$; dan sangat baik $>80,00$ (Widoyoko, 2017). Selain itu, data pre-test dan post-test hasil belajar dihitung dengan persamaan $n$-gain Hake (1998), kemudian disesuaikan dengan kriteria: $\langle\mathrm{g}\rangle\langle 0,3$ (rendah); 0,3 $\leq\langle\mathrm{g}\rangle \leq 0,7$ (sedang); dan $\langle\mathrm{g}\rangle\rangle$ 0,7 (tinggi).

\section{HASIL DAN PEMBAHASAN \\ Validitas bahan ajar CLIS}

Validitas bahan ajar diketahui melalui validasi untuk mengetahui kelayakan bahan ajar yang dikembangkan. Instrumen validasi memuat poin-poin standar kelayakan yang harus dimiliki oleh bahan ajar sehingga tergolong layak digunakan. Validitas bahan ajar terdiri dari validitas RPP, materi ajar, LKPD, dan THB. Hasil uji validitas bahan ajar secara ringkas dimuat dalam Tabel 1 berikut.

Tabel 1. Hasil validitas bahan ajar

\begin{tabular}{|c|c|c|c|c|c|}
\hline \multirow{2}{*}{\multicolumn{2}{|c|}{ Aspek Penilaian }} & \multicolumn{2}{|c|}{ Validitas } & \multicolumn{2}{|c|}{ Reliabilitas } \\
\hline & & Skor & Kategori & Skor & Kategori \\
\hline \multirow{3}{*}{ RPP } & Komponen RPP & 3,07 & Valid & \multirow{3}{*}{0,71} & \multirow{3}{*}{ Tinggi } \\
\hline & Bahasa & 3,00 & Valid & & \\
\hline & Isi RPP & 3,11 & Valid & & \\
\hline \multirow{3}{*}{ Materi Ajar } & Desain materi ajar & 3,06 & Valid & \multirow{3}{*}{0,86} & \multirow{3}{*}{$\begin{array}{l}\text { Sangat } \\
\text { Tinggi }\end{array}$} \\
\hline & Bahasa & 3,04 & Valid & & \\
\hline & Isi materi ajar & 3,08 & Valid & & \\
\hline \multirow{4}{*}{ LKPD } & Desain LKPD & 3,18 & Valid & \multirow{4}{*}{0,82} & \multirow{4}{*}{$\begin{array}{l}\text { Sangat } \\
\text { Tinggi }\end{array}$} \\
\hline & Format & 3,21 & Valid & & \\
\hline & Bahasa & 3,00 & Valid & & \\
\hline & Isi LKPD & 3,05 & Valid & & \\
\hline THB & Konstruksi umum & 3,05 & Valid & 0,71 & Tinggi \\
\hline
\end{tabular}

RPP merupakan rancangan prosedur yang dibuat oleh guru untuk satu kali pertemuan atau lebih. RPP mengacu pada kurikulum 2013 revisi sesuai dengan kurikulum yang diterapkan pada kelas sasaran uji coba. Tabel 1 menunjukkan bahwa aspek penilaian RPP yang terdiri dari aspek komponen, bahasa, dan isi RPP berkategori valid sehingga disimpulkan RPP secara keseluruhan berkategori valid 
Hartati, L., Wati, M., \& Suyidno. (2021). Pengembangan Bahan Ajar dengan Model Children Learning in Science (CLIS) untuk Meningkatkan Aktivitas dan Keterampilan Proses Sains Peserta Didik.

dengan derajat reliabilitas tinggi. Selanjutnya dilakukan revisi sesuai saran dari validator. Daryanto \& Dwicahyono (2014); Fajeriadi dkk. (2019) menjelaskan bahwa perumusan tujuan pembelajaran yang ada dalam RPP harus memiliki alur pikir yang berkaitan, baik dari standar kompetensi (SK), kompetensi dasar (KD), indikator, dan tujuan pembelajaran dimana tujuan pembelajaran ini disusun dalam kalimat operasional.

Materi ajar yaitu seperangkat materi yang disusun secara sistematis baik secara tertulis maupun tidak, kemudian diajarkan dalam kegiatan pembelajaran. Tabel 1, menunjukkan skor aspek penilaian materi ajar yang terdiri dari aspek desain, bahasa, dan isi materi ajar berkategori valid sehingga disimpulkan materi ajar secara keseluruhan berkategori valid dengan derajat reliabilitas sangat tinggi. Materi ajar selanjutnya direvisi sesuai dengan saran dari validator. Hasil validitas yang berkategori valid ini menggambarkan bahwa materi ajar yang dikembangkan telah memenuhi standar komponen materi ajar yang baik. Sejalan dengan Permendikbud No. 8 Tahun 2016 bahwa materi ajar yang layak digunakan oleh pendidik wajib memenuhi aspek materi, aspek kebahasaan, aspek penyajian materi, dan aspek kegrafikan.

LKPD adalah lembaran yang berisi tugas sebagai petunjuk bagi peserta didik dalam memahami materi untuk dapat mencapai tujuan pembelajaran. LKPD yang dikembangkan disesuaikan dengan model pembelajaran CLIS. Tabel 1, menunjukkan bahwa aspek penilaian LKPD yang terdiri dari aspek desain, format, bahasa, dan isi LKPD berkategori valid sehingga disimpulkan LKPD secara keseluruhan berkategori valid dengan derajat reliabilitas sangat tinggi. LKPD selanjutnya direvisi sesuai dengan saran-saran dari validator. LKPD harus disusun dengan format dan desain yang menarik sehingga mudah dibaca dan berorientasi antara materi yang diajarkan dengan situasi di dunia nyata sehingga peserta didik aktif menyelesaikan permasalahan yang berkaitan dengan LKPD tersebut (Herman, 2015).

THB ialah butir tes yang digunakan untuk mengetahui hasil belajar peserta didik setelah selesai mengikuti kegiatan belajar mengajar. THB digunakan untuk mengukur efektivitas pembelajaran yang telah dilaksanakan menggunakan bahan ajar yang didesain, berisi 8 soal yang disesuaikan dengan jumlah tujuan pembelajaran. Tabel 1, menunjukkan bahwa skor konstruksi umum dan validitas butir memperoleh kategori valid sehingga disimpulkan THB secara keseluruhan berkategori valid dengan derajat reliabilitas tinggi. THB selanjutnya direvisi sesuai dengan saran-saran dari validator. Penyusunan THB harus menggunakan kalimat yang jelas dan tidak menimbulkan penafsiran ganda (Daryanto \& Dwicahyono, 2014).

Dari hasil temuan di atas, diketahui bahwa validitas RPP, materi ajar, LKPD, dan THB berkategori valid. Sehingga dapat disimpulkan bahwa validitas bahan ajar berkategori valid dengan derajat reliabilitas tinggi.

\section{Kepraktisan bahan ajar CLIS}

Kepraktisan bahan ajar dengan model CLIS diukur berdasarkan keterlaksanaan RPP. Hasil pengamatan keterlaksanaan RPP untuk seluruh pertemuan secara ringkas dimuat pada Tabel 2 berikut.

Tabel 2. Hasil pengamatan keterlaksanaan RPP

\begin{tabular}{lcccc}
\hline \multicolumn{1}{c}{ Fase } & \multicolumn{4}{c}{ Skor } \\
& $\mathbf{1}$ & $\mathbf{2}$ & $\mathbf{3}$ & $\mathbf{4}$ \\
\hline 1. Orientasi & $79,25(\mathrm{~B})$ & $87,50(\mathrm{SB})$ & $91,75(\mathrm{SB})$ & $93,75(\mathrm{SB})$ \\
2. Pemunculan gagasan & $75,00(\mathrm{~B})$ & $75,00(\mathrm{~B})$ & $87,50(\mathrm{SB})$ & $87,50(\mathrm{SB})$ \\
3. Penyusunan ulang gagasan & $80,75(\mathrm{SB})$ & $82,50(\mathrm{SB})$ & $87,50(\mathrm{SB})$ & $92,00(\mathrm{SB})$ \\
4. Penerapan gagasan & $68,75(\mathrm{~B})$ & $70,00(\mathrm{~B})$ & $81,25(\mathrm{SB})$ & $81,25(\mathrm{SB})$ \\
5. Pemantapan gagasan & $81,25(\mathrm{SB})$ & $82,50(\mathrm{SB})$ & $89,50(\mathrm{SB})$ & $91,75(\mathrm{SB})$ \\
\hline Reliabilitas
\end{tabular}

Keterangan: SB = Sangat Baik; B = Baik; ST = Sangat Tinggi

Berdasarkan Tabel 2, keterlaksanaan RPP pertemuan 1 seluruh fase berkategori baik, kecuali fase 3 dan 5 berkategori sangat baik. Pertemuan 2 RPP fase 1, 3, dan 5 berkategori sangat baik dan fase 2 dan 4 berkategori baik. Pertemuan 3 seluruh fase berkategori sangat baik, dan pertemuan 4 setiap fase juga berkategori sangat baik. Hal tersebut menunjukkan bahwa langkah-langkah pembelajaran yang ada pada RPP telah terlaksana dengan baik dalam semua pertemuan. Perolehan rata-rata seluruh pertemuan meningkat dari pertemuan 1 sampai 4. Sehingga secara keseluruhan keterlaksanaan 
RPP berkategori sangat baik dan dapat disimpulkan bahwa bahan ajar berkategori sangat praktis dengan reliabilitas berkategori sangat tinggi. Sejalan dengan pendapat Purboningsih (2015) apabila antara kurikulum dengan proses pembelajaran konsisten, maka bahan ajar dapat dikatakan praktis. Widoyoko (2017) menjelaskan bahwa bahan ajar dikatakan praktis jika memiliki kepraktisan yang tinggi serta mudah pengadministrasiannya.

\section{Efektivitas bahan ajar CLIS}

Pencapaian aktivitas menentukan bagaimana pengaruh bahan ajar yang didesain dalam meningkatkan aktivitas peserta didik, meskipun penilaian dilakukan per kelompok saja. Hasil pencapaian aktivitas peserta didik secara ringkas dimuat pada Tabel 3 berikut.

Tabel 3. Hasil pencapaian aktivitas peserta didik

\begin{tabular}{lcccc}
\hline \multicolumn{1}{c}{ Aspek } & $\mathbf{1}$ & $\mathbf{2}$ & $\mathbf{3}$ & $\mathbf{4}$ \\
\hline Mendengarkan/memperhatikan penjelasan guru & $64,50(\mathrm{~B})$ & $79,25(\mathrm{~B})$ & $89,50(\mathrm{SB})$ & $87,50(\mathrm{SB})$ \\
Berdiskusi dengan peserta didik lain & $62,50(\mathrm{~B})$ & $73,00(\mathrm{~B})$ & $91,75(\mathrm{SB})$ & $91,75(\mathrm{SB})$ \\
Mendengarkan pendapat teman/kelompok lain & $50,00(\mathrm{CB})$ & $56,25(\mathrm{CB})$ & $77,00(\mathrm{SB})$ & $85,50(\mathrm{SB})$ \\
Mengungkapkan pendapat & $70,75(\mathrm{~B})$ & $66,75(\mathrm{~B})$ & $83,25(\mathrm{SB})$ & $91,75(\mathrm{SB})$ \\
Bekerjasama dengan peserta didik lain & $66,75(\mathrm{~B})$ & $87,50(\mathrm{SB})$ & $87,50(\mathrm{SB})$ & $95,75(\mathrm{SB})$ \\
\hline
\end{tabular}

Keterangan: $\mathrm{K}=$ Kategori; $\mathrm{SB}=$ Sangat Baik; $\mathrm{B}=$ Baik; $\mathrm{CB}=$ Cukup Baik

Tabel 3 menunjukkan bahwa pada pertemuan 1, setiap indikator yang ditingkatkan berkategori baik, kecuali pada indikator mendengarkan pendapat teman/kelompok lain berkategori cukup baik dikarenakan peserta didik asik dengan kelompoknya sendiri. Pertemuan 2 setiap indikator yang ditingkatkan berkategori baik dan sangat baik, kecuali pada indikator mendengarkan pendapat teman/kelompok lain berkategori cukup baik meskipun rata-ratanya mengalami kenaikan dan pada indikator mengungkapkan pendapat mengalami penurunan skor dibandingkan pertemuan 1 meskipun berkategori baik. Pertemuan 3 hampir setiap indikator yang ditingkatkan berkategori sangat baik, kecuali pada indikator mendengarkan pendapat teman/kelompok lain berkategori baik. Pertemuan 4 semua indikator berkategori sangat baik. Nilai rata-rata yang diperoleh untuk masing-masing indikator pada setiap pertemuan juga mengalami peningkatan dari pertemuan satu ke pertemuan selanjutnya. Hasil pengamatan ini sejalan dengan pendapat Marlina dkk. (2013) bahwa model CLIS dapat membiasakan peserta didik belajar mandiri dalam memecahkan suatu masalah, berpikir kreatif, berdiskusi dengan teman, mengemukakan pendapatnya sendiri dan membiasakan peserta didik saling bekerja sama serta terlibat secara langsung dalam melakukan kegiatan sehingga aktivitas peserta didik dapat meningkat. Penjelasan di atas disimpulkan bahwa bahan ajar yang dikembangkan dapat dikatakan efektif digunakan dalam proses pembelajaran untuk meningkatkan aktivitas peserta didik.

Pencapaian KPS peserta didik menentukan bagaimana pengaruh bahan ajar yang didesain dalam meningkatkan KPS peserta didik, meskipun penilaian dilakukan per kelompok saja. Hasil pencapaian KPS peserta didik secara ringkas dimuat pada Tabel 4 berikut.

Tabel 4. Hasil pencapaian KPS peserta didik

\begin{tabular}{lcccc}
\hline \multicolumn{1}{c}{ Indikator } & \multicolumn{4}{c}{ Skor } \\
& $\mathbf{1}$ & $\mathbf{2}$ & $\mathbf{3}$ & $\mathbf{4}$ \\
\hline Merumuskan hipotesis & $68,75(\mathrm{~B})$ & $85,42(\mathrm{SB})$ & $97,92(\mathrm{SB})$ & $100,00(\mathrm{SB})$ \\
Identifikasi dan definisi operasional variabel & $39,58(\mathrm{~KB})$ & $83,33(\mathrm{SB})$ & $93,75(\mathrm{SB})$ & $100,00(\mathrm{SB})$ \\
Melakukan percobaan & $70,83(\mathrm{~B})$ & $87,50(\mathrm{SB})$ & $87,50(\mathrm{SB})$ & $93,75(\mathrm{SB})$ \\
Menganalisis data & $77,08(\mathrm{~B})$ & $93,75(\mathrm{SB})$ & $100,00(\mathrm{SB})$ & $100,00(\mathrm{SB})$ \\
Membuat kesimpulan & $72,92(\mathrm{~B})$ & $79,17(\mathrm{~B})$ & $93,75(\mathrm{SB})$ & $100,00(\mathrm{SB})$ \\
\hline
\end{tabular}

Tabel 4 menunjukkan bahwa pada pertemuan 1, setiap indikator yang ditingkatkan berkategori baik, kecuali pada indikator mengidentifikasi dan mendefinisi operasional variabel berkategori kurang baik. Pertemuan 2 setiap indikator yang ditingkatkan berkategori sangat baik, kecuali pada indikator membuat kesimpulan berkategori baik. Pertemuan 3 dan pertemuan 4 semua indikator berkategori sangat baik. Nilai rata-rata yang diperoleh untuk masing-masing indikator pada setiap pertemuan juga mengalami peningkatan dari pertemuan satu ke pertemuan selanjutnya. Sejalan dengan pendapat Utami dkk. (2015) bahwa model CLIS adalah kerangka berpikir untuk menciptakan lingkungan yang 
Hartati, L., Wati, M., \& Suyidno. (2021). Pengembangan Bahan Ajar dengan Model Children Learning in Science (CLIS) untuk Meningkatkan Aktivitas dan Keterampilan Proses Sains Peserta Didik.

memungkinkan terjadinya kegiatan belajar mengajar yang melibatkan peserta didik dalam kegiatan pengamatan dan percobaan dengan menggunakan LKPD. Penjelasan di atas menggambarkan bahwa bahan ajar yang didesain dapat dikatakan efektif digunakan dalam proses pembelajaran untuk meningkatkan KPS peserta didik.

Hasil belajar diukur menggunakan THB yang diberikan sebelum materi diajarkan menggunakan bahan ajar (pre-test) dan setelah materi diajarkan (post-test). Soal yang disajikan pada THB terdiri dari 8 soal untuk mengukur kemampuan kognitif peserta didik. Hasil pre-test dan post-test kemudian digunakan untuk menghitung $N$-gain. Hasil perhitungan $N$-gain yang diperoleh dimuat dalam Tabel 5 berikut.

Tabel 5. Hasil perhitungan $N$-gain

\begin{tabular}{cccc}
\hline Pre-test & Post-test & $\langle g\rangle$ & Kategori \\
\hline 10,82 & 58,17 & 0,62 & Sedang \\
\hline
\end{tabular}

Hasil belajar peserta didik untuk mengetahui efektivitas pembelajaran menggunakan bahan ajar model CLIS. Hasil dari nilai rata-rata pre-test yang diperoleh yaitu sebesar 10,82 dan rata-rata nilai post-test sebesar 58,17 dengan perolehan Gain Score sebesar 0,62 yang berkategori sedang. Rata-rata nilai pre-test masih rendah, karena kondisi awal peserta didik yang belum mempelajari materi yang dikembangkan. Rata-rata nilai post-test menunjukan tidak tercapainya KKM. Peserta didik yang memenuhi Kriteria Ketuntasan Minimal (KKM) dengan nilai 75 berdasarkan hasil post-test hanya berjumlah 6 orang. Meskipun demikian, hasil $N$-Gain yang diperoleh berkategori sedang karena dari nilai pre-test dan post-test mengalami kenaikan, sehingga dapat dikatakan bahwa bahan ajar efektif digunakan dalam pembelajaran. Sejalan dengan pendapat Aritonang (2008) bahwa faktor instrumen yaitu bahan ajar yang terdiri dari RPP, materi ajar, LKPD, dan THB yang dirancang oleh guru dapat mempengaruhi hasil belajar peserta didik. Anisah dkk., (2016) menyatakan bahwa bahan ajar dapat dikatakan efektif ketika memberikan hasil sesuai dengan tujuan pembelajaran yang dicapai dan bergantung pada proses pembelajaran yang dilalui peserta didik tersebut. Adapun kelemahan dalam penelitian pengembangan ini antara lain, peserta didik yang mencapai KKM setelah mengerjakan posttest masih sedikit yaitu sebesar $20,00 \%$ dari 30 peserta didik serta peningkatan aktivitas dan KPS peserta didik yang diperoleh melalui lembar pengamatan aktivitas dan KPS masih bersifat secara kelompok.

\section{SIMPULAN}

Bahan ajar dengan model CLIS layak digunakan untuk meningkatkan aktivitas dan KPS peserta didik karena temuan hasil penelitian yang menunjukkan; (1) Hasil validasi RPP, materi ajar, LKPD, dan THB berkategori valid, (2) keterlaksanaan RPP berkategori sangat baik, 3) aktivitas dan keterampilan proses sains peserta didik berkategori sangat baik serta $\mathrm{N}$-gain hasil belajar kognitif peserta didik berkategori sedang. Bahan ajar model CLIS untuk meningkatkan aktivitas dan KPS ini diharapkan ada penelitian lebih lanjut untuk desain bahan ajar ini menjadi lebih baik lagi dan diterapkan pada materi-materi yang lainnya

\section{DAFTAR PUSTAKA}

Anisah, A., Wati, M., \& Mahardika, A.I. (2016). Pengembangan Perangkat Pembelajaran Getaran dan Gelombang dengan Model Inkuiri Terstruktur untuk Siswa Kelas VIII A SMPN 31 Banjarmasin. Berkala Ilmiah Pendidikan Fisika, 4 (1), 1-12.

Arikunto, S. (2014). Prosedur Penelitian suatu Pendekatan Praktik. Jakarta: PT Rineka Cipta.

Aritonang, K.T. (2008). Minat dan Motivasi dalam Meningkatkan Hasil Belajar Siswa. Jurnal Pendidikan Penabur, 7 (10), 11-21.

Chodijah, S., Fauzi, A., \& Wulan, R. (2012). Pengembangan Perangkat Pembelajaran Fisika Menggunakan Model Guided Inquiry yang Dilengkapi Penilaian Portofolio pada Materi Gerak Melingkar. Jurnal Penelitian Pembelajaran Fisika, 1 (1), 1-19.

Daryanto \& Dwicahyono, A. (2014). Pengembangan Perangkat Pembelajaran. Yogyakarta: Gava Media.

Elnada, I.W., Mastuang., \& Salam, A. (2016). Meningkatkan Keterampilan Proses Sains dengan Model Inkuiri Terbimbing pada Siswa Kelas X MIA 3 di SMAN 3 Banjarmasin. Berkala Ilmiah Pendidikan Fisika, 4 (3), 228-236. 
Fahmi \& Irhasyuarna, Y. (2019). Pengantar Pendidikan: Manusia, Pendidikan, dan Perkembangan Zaman. Banjarmasin: Program Studi Magister Keguruan IPA PPs ULM.

Fahmi., Setiadi, I., Elmawati, D., \& Sunardi. (2019). Discovery Learning Method for Training Critical Thinking Skills of Students. European Journal of Education Studies, 6 (3), 342-351. Doi: 10.5281/zenodo.3345924.

Fahmi. (2016). Strategi Pembelajaran Contextual Teaching and Learning untuk Meningkatkan Keterampilan Berpikir Tingkat Tinggi. Prosiding Seminar Nasional Pendidikan IPA "Mengembangkan Keterampilan Berpikir Tingkat Tinggi Melalui Pembelajaran IPA”. S2 IPA Unlam Press. Banjarmasin, Indonesia. ISBN. 978-602-60213-0-4.

Fajeriadi, H., Zaini, M., \& Dharmono. (2019). The Validity of the Gastropods Popular Scientific Book in the Pulau Sembilan Kotabaru Coastal Area. Journal of Biology Education, 8 (2), 142-149.

Hake, R.R. (1998). Interactive-Engagement Versus Traditional Methods: A Six-Thousand-Student Survey of Mechanics Test Data for Introductory Physics Courses. American Journal of Physics, $66(1), 64-74$.

Herman. (2015). Pengembangan LKPD Tekanan Hidrostatik Berbasis Keterampilan Proses Sains. Jurnal Sains dan Pendidikan Fisika, 11 (2), 120-131.

Hidayati, H., Hartono, H., \& Mujamil, J. (2015). Penerapan Model Pembelajaran Children Learning in Science (CLIS) untuk Meningkatkan Hasil Belajar Siswa di Kelas XI IPA SMAN 3 Palembang. Jurnal Penelitian Pendidikan Kimia: Kajian Hasil Penelitian Pendidikan Kimia, 2 (1), 23-34.

Ismail, A. (2017). Penerapan Model Pembelajaran Children Learning in Science (CLIS) berbantuan Multimedia untuk Meningkatkan Keterampilan Proses Sains Siswa SMA pada Pokok Bahasan Fluida. JIPFRI (Jurnal Inovasi Pendidikan Fisika dan Riset Ilmu, 1 (2), 83-87.

Joko, T., Ahdinirwanto, R.W., \& Maftukhin, A. (2013). Peningkatan Kemampuan Berpikir Kritis Melalui Model Pembelajaran Children Learning in Science (CLIS) pada Siswa Kelas VIII SMP Negeri 1 Mirit Tahun Pelajaran 2012/2013. RADIASI, 3 (2), 112-115.

Laili, Y.N., Mahardika, I.K., \& Ghani, A. A. (2015). Pengaruh Model Children Learning in Science (CLIS) disertai LKS Berbasis Multirepresentasi terhadap Aktivitas Belajar Siswa dan Hasil Belajar Siswa dalam Pembelajaran Fisika di SMA Kabupaten Jember. Jurnal Pembelajaran Fisika, 4 (2), 171-175.

Mahfuziannor, M., Suyidno., \& An'nur, S. (2014). Pengembangan Lembar Kegiatan Siswa (LKS) dan Media Penunjang Materi Ajar untuk Melatihkan Keterampilan Proses Sains. Berkala Ilmiah Pendidikan Fisika, 2 (1), 78-88.

Manu, S.T.N \& Nomleni, F.T. (2018). Pengaruh Metode Pembelajaran Karya Kelompok terhadap Keterampilan Proses Sains dengan Kovariabel Kemampuan Berpikir Kreatif Siswa pada Mata Pelajaran Biologi. Scholaria: Jurnal Pendidikan dan Kebudayaan, 8 (2), 167-179.

Marlina, M., Zainuddin., \& An'nur, S. (2013). Keefektifan Model Children Learning in Science (CLIS) untuk Meningkatkan Keterampilan Berpikir Rasional Siswa. Berkala Ilmiah Pendidikan Fisika, 1 (3), 237-244.

Maulida, H., Syahmani., \& Sari, M.M. (2020). Implementasi Strategi REACT Terhadap Hasil Belajar dan Keterampilan Sosial Peserta Didik. Journal of Banua Science Education (JBSE), 1 (1), 7 14. E- ISSN: 2745-7222. Doi: 10.20527/jbse.vli1.6. http://jbse.ulm.ac.id/index.php/JBSE/issue/view/2

Ningtyas, T.R., Susilowati, E., Suyidno., \& Zainuddin. (2020). Desain Perangkat Pembelajaran Kooperatif Berbasis Eksperimen untuk Meningkatkan Tanggung Jawab dan Pemahaman Konsep Peserta didik dalam Pembelajaran Fisika. Journal of Banua Science Education (JBSE), 1 (1), 43-50. E- ISSN: 2745-7222. Doi: 10.20527/jbse.v1i1.7. http://jbse.ulm.ac.id/index.php/JBSE/issue/view/2

Permendikbud. (2016). Peraturaana Menteri Pendidikan dan Kebudayaan Nomor 8 Tahun 2016 tentang Standar Proses Pendidikan Dasar dan Menengah. Jakarta: Kementrian Pendidikan dan Kebudayaan Republik Indonesia.

Purboningsih, D. (2015). Pengembangan Perangkat Pembelajaran dengan Pendekatan Guided Discovery pada Materi Barisan dan Deret untuk Siswa SMK Kelas X. Prosiding Seminar Nasoinal Matematika dan Pendidikan Matematika UNY, 467-474.

Purnamasari, U.A., Arifuddin, M., \& Hartini, S. (2018). Meningkatkan Aktivitas Belajar Siswa pada Mata Pelajaran IPA dengan Model Pembelajaran Koperatif Tipe Group Investigation. Berkala 
Hartati, L., Wati, M., \& Suyidno. (2021). Pengembangan Bahan Ajar dengan Model Children Learning in Science (CLIS) untuk Meningkatkan Aktivitas dan Keterampilan Proses Sains Peserta Didik.

Ilmiah Pendidikan Fisika, 6 (1), 130-141.

Rahmawati, I., Mastuang., Suyidno., \& Sunarti, T. (2020). Kelayakan Bahan Ajar Elastisitas dan Hukum Hooke Berbasis Inkuiri Terbimbing untuk Melatihkan Keterampilan Proses Sains Peserta Didik. Journal of Banua Science Education (JBSE), 1 (1), 21-28. E- ISSN: 2745-7222. Doi: 10.20527/jbse.v1i1.1. http://jbse.ulm.ac.id/index.php/JBSE/issue/view/2

Renjani, M.K.D., Susilawati., \& Khoiri, N. (2018). Deskripsi Kemampuan Berpikir Kritis Siswa SMA melalui Model Pembelajaran CLIS (Children Learning in Science) berbantuan LKS pada Materi Elastisitas dan Hukum Hooke. Jurnal Penelitian Pembelajaran Fisika, 9 (1), 21-27.

Rosa, F.O. (2015). Pengembangan Modul Pembelajaaran IPA SMP pada Materi Tekanan berbasis Keterampilan Proses Sains. Jurnal Pendidikan Fisika, 3 (1), 49-63.

Satoso, B.P \& Wulandari, F.E. (2020). Pengaruh Pembelajaran Berbasis Proyek Dipadu dengan Metode Pemecahan Masalah pada Keterampilan Berpikir Kreatif Siswa. Journal of Banua Science Education (JBSE), 1 (1), 1-6. E- ISSN: 2745-7222. Doi: 10.20527/jbse.v1i1.3. http://jbse.ulm.ac.id/index.php/JBSE/issue/view/2

Utami, M.P., Indrawati, I., \& Sutarto, S. (2015). Model Pembelajaran Children Learning in Science (CLIS) dalam Pembentukan Konsep Fisika Siswa SMA di Kabupaten Jember (Materi Pokok Elastisitas Zat Padat dan Hukum Hooke). Artikel Ilmiah Mahasiswa, 2 (1), 1-5.

Widoyoko, E.P. (2017). Evaluasi Program Pembelajaran. Yogyakarta: Pustaka Belajar.

\section{UCAPAN TERIMA KASIH}

Terima kasih kami sampaikan kepada Program Studi Pendidikan Fisika FKIP ULM dan SMAN 8 Banjarmasin yang telah mengijinkan dan memfasilitasi kegiatan penelitian ini. 